\title{
Finite Element Modeling of Early Stage Self-loosening of Bolted Joints Haoliang $\mathrm{Xu}^{1, \mathrm{a}}$, Lihua Yang ${ }^{1, \mathrm{~b}, *}$, Lie $\mathrm{Yu}^{1,2, \mathrm{c}}$ \\ ${ }^{1}$ State Key Laboratory for Strength and Vibration of Mechanical Structures, Xi'an Jiaotong University, Xi'an 710049, Shaanxi, China \\ ${ }^{2}$ School of Mechanical Engineering, Xi'an Jiaotong University, 28 West Xianning Road, Xi'an 710049, Shaanxi, China
}

aemail:877280489@qq. com, ${ }^{\text {bemail:yang1ihua_2@126.com, }{ }^{c} e m a i l: y u l i e @ m a i 1 . x j t u . e d u . c n ~}$

Keywords: Bolted Joints; Self-loosening; Clamping Force

\begin{abstract}
Bolted joints is one of the most widely used connections due to relatively simple structure, easy accessibility and reliability. However, Bolted Joints will gradually lose the clamping force under cyclic external loading, especially transverse loading. In order to fully reveal the nature of early stage self-loosening of bolted joints, in view of the common bolted joints of grade 6.8, this paper firstly establishes the elastic finite element model, and analyzes the change of clamping force under different pre displacement. The results show that the clamping force is proportional to the pre displacement. Then, in view of the common bolted joints of grade 6.8 under transverse cyclic loading, this paper establishes the elastic-plastic finite element model, and simulates the process of early stage self-loosening of bolted joints under different lateral cyclic load amplitude, different initial preload, and different clamping surface friction coefficient. It can be seen that the early stage self-loosening of bolted joints under lateral cyclic loading is due to the accumulation of local cyclic plastic deformation at the root of the engaged thread. The bigger lateral cyclic loading amplitude leads to the faster self-loosening. The greater preload will result in a greater remaining clamping force. There is almost no relationship between the friction coefficient of clamping surface and the self-loosening of bolted joints. Reasonable preload can effectively improve the bolted connection relaxation.
\end{abstract}

\section{Introduction}

Bolted joint is one of the most widely used due to relatively simple structure, easy accessibility and reliability. The failure of bolted joints is also one of the main reasons which can lead to the equipment running accidents. Generally, potential durability problems in machine or structure are proportional to the number of the bolted joints used. Therefore, the research on bolted joints has recently been very active. A variety of failure will be occurred in bolted connection under the actual loading conditions. Bolted joints will lead to screw fracture under an overload condition, and cause fatigue and self-loosening under cyclic loading. Under the condition of high temperature, material creep will occur in the process of use, eventually leading to the stress relaxation of bolted connections. Self-loosening is the gradual loss of the clamping force in the bolted connections under cyclic external loading, especially transverse loading, eventually leading to the failure of bolted joints. Early investigations concentrated on the behavior of bolted joints under axial dynamic loading. Junker firstly noticed the importance of the lateral dynamic load to the occurrence of self-loosening. It is generally considered that the clamping force acts as the source of internal off-torque force which leads to the rotational loosening of the bolted joint[1]. Such a theory cannot explain the experimental observation that significant loss of preload can occur before the nut starts to back off. Yamamoto and Kasei developed quantitative models based on a two-stage theory for the nut to slide along the thread of the bolt [2]. However, no quantitative results were provided for the verification of the models.

Complying with Junker's basic assumptions, Sakai carried on conducting a theoretical analysis, 
attempting to derive the conditions necessary for a bolt to loosen by self-rotation. It was summed that unless the friction coefficient was less than 0.03 , the bolt would not rotate loosely. It was found that one of the causes of the clamping force relaxation was the fretting wear between contact surfaces $[3,4]$.

Kasei et al. firstly studied self-loosening concentrating on the initial stage of the loosening. The initial loss of the clamping force was attributed to the repeated twist of the nut relative to the bolt shank because of the slippage between the bolt and nut threads [5]. Yanyao Jiang and Ming Zhang proposed that bolted joints will occur self-loosening based on self-designed experimental device, and revealed that the self-loosening process can be divided into two distinguishable stages. The first stage is featured by a short and sharp clamping force reduction with no relative rotation between the nut and the bolt. In the second stage, clamping force is gradually reduced as the nut rotates [6,7].

This paper mainly establishes common bolted joints model of grade 6.8 under lateral cyclic loads based on the finite element simulation, and analyzes the early stage self-loosening of bolted joints under lateral cyclic loading.

\section{Research on the relationship between the pre displacement and clamping force}

The elastic finite element model is established in view of the common bolted joints of grade 6.8 which is shown in Fig.1. Screw thread is simplified as a trapezoidal groove. As bolted joints and loading are Central symmetric, considering the computer calculation time, this paper establishes $1 / 4$ elastic finite element model. Fig. 1 is a common bolt and nut clamping two truncated cone. Bolted joint is grade 6.8. Yield strength limit of the material is $480 \mathrm{MPa}$. Strength limit is $600 \mathrm{MPa}$. Elastic modulus $\mathrm{E}=2.06 \mathrm{e} 11 \mathrm{~Pa}$, Poisson's ratio $\mathrm{V}=0.3$. Six hexagon head trapezoidal thread connection is M12x1.75. The two connected parts are truncated cone. The inner radius is $6 \mathrm{~mm}$, and the outer radius is $24 \mathrm{~mm}$. The thickness of clamping part 1 is $27 \mathrm{~mm}$, and that of clamping part 2 is $26.09 \mathrm{~mm}$. There are the contacts between the five engaged threads of the bolt and the nut, the contact between the nut and its bearing surface, the contact between the two camped plates, and the contact between the bolt head and its bearing surface.

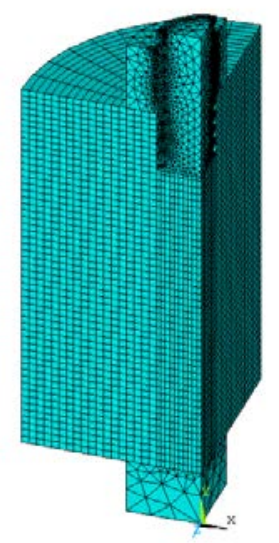

Fig.1 Elastic finite element model of bolted joints

Pre displacement is the initial extended length of the screw. Set the different pre displacement: $0.02 \mathrm{~mm}, 0.04 \mathrm{~mm}, 0.06 \mathrm{~mm}, 0.08 \mathrm{~mm}, 0.10 \mathrm{~mm}$. Integrating the cross section of the screw, the different clamping force can be obtained The results are shown as Fig.2. It is concluded that the clamping force is proportional to the pre displacment. 


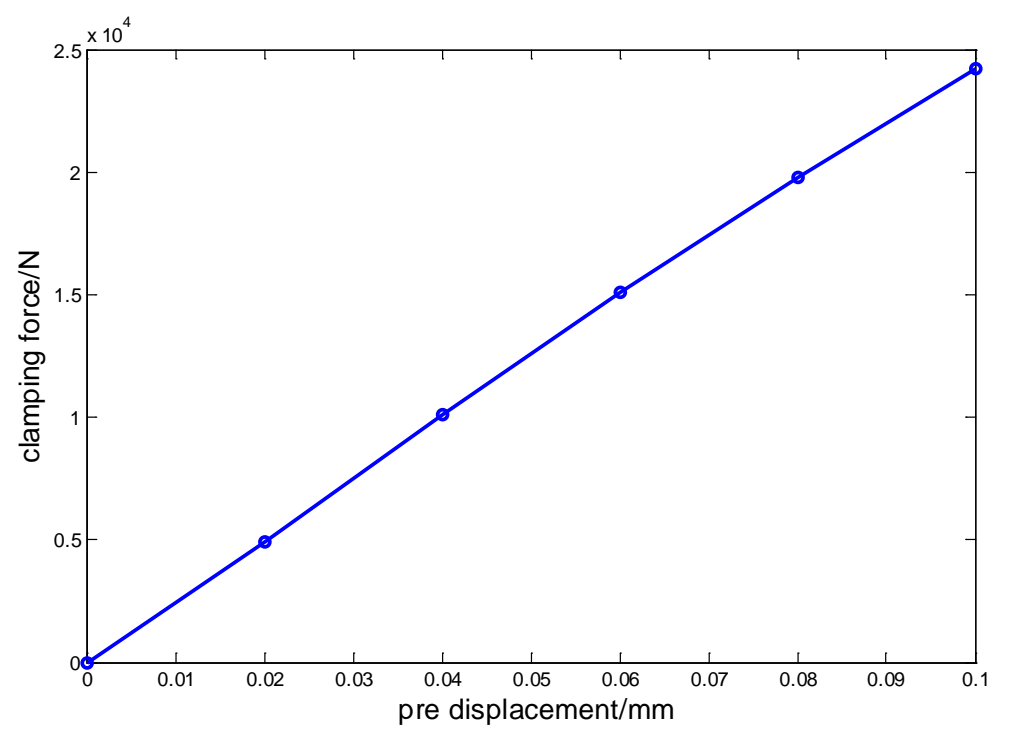

Fig.2 The relationship between the pre tension and clamping force

\section{Modeling the early stage self-loosening of bolted joints and analyzing the influence factors}

Establishing the elastic finite element model in view of the common bolted joints of grade 6.8 is shown in Fig.3. Screw thread is simplified as a trapezoidal groove, because there is no relative rotation between bolt and nut. Bolt connection and loading are symmetric about one plane. Considering the computer calculation time, this paper establishes $1 / 2$ elastic-plastic finite element model. As the bolted joint is working under transverse cyclic loading, the clamping parts are set as block with a hole. The hole radius is $6.6 \mathrm{~mm}$, a square side length of the bottom surface is $48 \mathrm{~mm}$, and height is $25 \mathrm{~mm}$. In addition, there is a gasket. The gasket is mainly used to produce preload of bolted joints, because the gasket will expansion after heating. The coefficient of expansion is $1.0 \mathrm{e}-4 /{ }^{\circ} \mathrm{C}$. For example, the gasket is respectively heating to $267.5585^{\circ} \mathrm{C}$ and $200.6689{ }^{\circ} \mathrm{C}$, corresponding to the pre displacement $0.08 \mathrm{~mm}$ and $0.06 \mathrm{~mm}$. The selection of expansion coefficient does not have other practical significance. Gasket outer diameter is $12 \mathrm{~mm}$, inner diameter is $6.6 \mathrm{~mm}$, and thickness is $2.99 \mathrm{~mm}$. Other parameters about the bolted joints are same as the above section. During the simulation, the left surface the lower clamping part is fixed, while the right surface of the upper clamping part is subjected to transverse cyclic displacement loading.

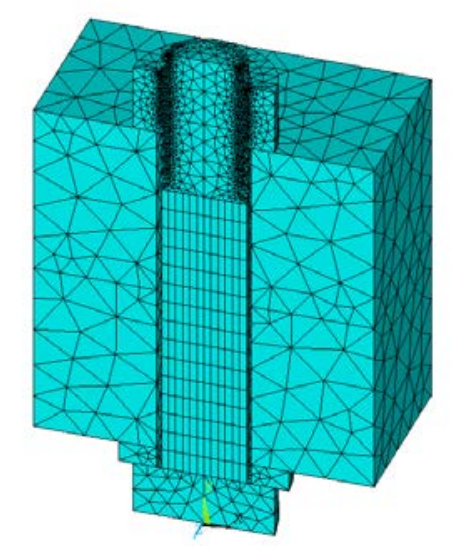

Fig.3 Elastic-plastic finite element model of bolted joints

Firstly, the friction coefficient of the contacts is set as 0.3 , pre displacement respectively is $0.08 \mathrm{~mm}$ and $0.06 \mathrm{~mm}$. The magnitude of the transverse cyclic displacement loading is $0.46 \mathrm{~mm}$. 
Simulating of six load cycles, the change of clamping force with the load cycle can be obtained as shown in Fig.4. From Fig.4, it can be concluded that the greater preload will lead to a greater remaining clamping force, but the great preload make the self-loosening more quickly.

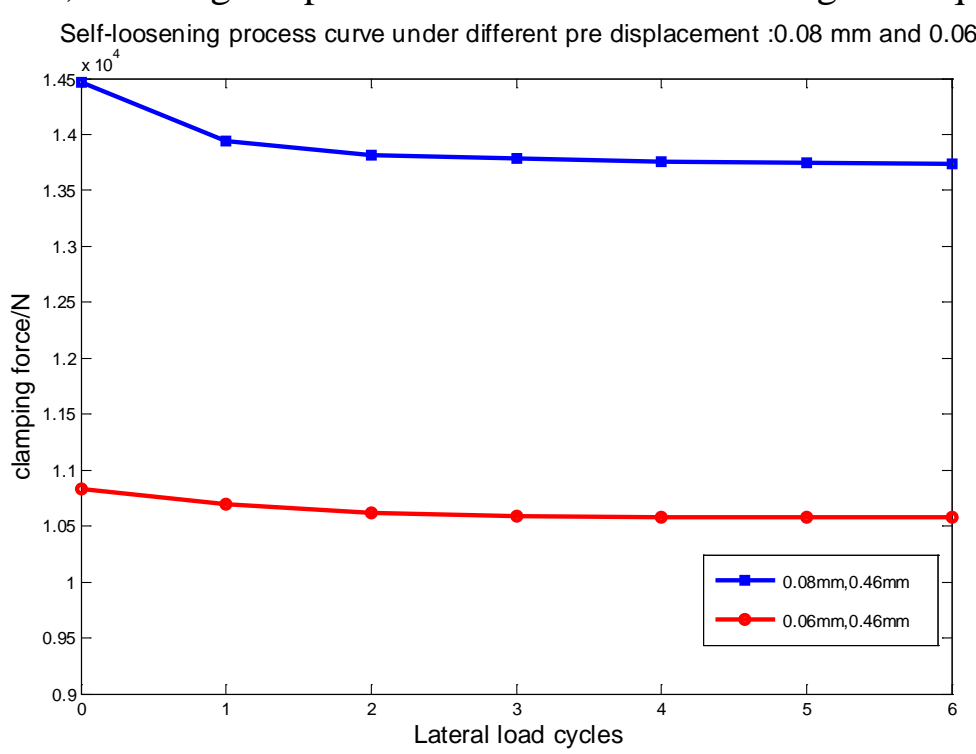

Fig.4 Self-loosening process curve under different preload

The von Mises stress distribution under the first cyclic lateral loading is shown as Fig.5. From the Fig.5, it can be obviously seen that local cyclic plastic deformation the root of the engaged thread occurred. So the early stage self-loosening of bolted joints under lateral cyclic loading is due to the accumulation of local cyclic plastic deformation at the root of the engaged thread.

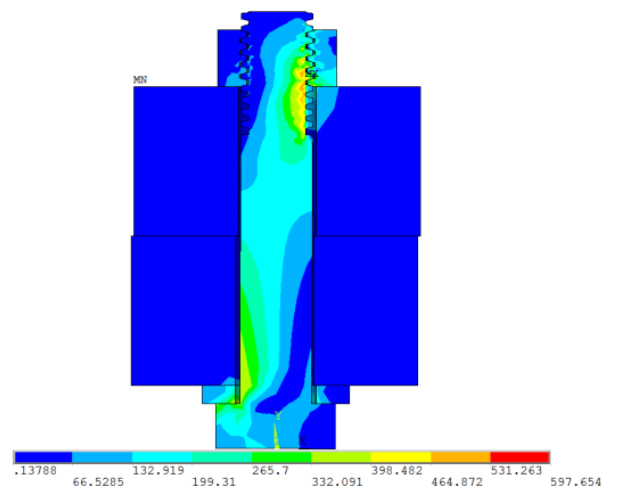

a)

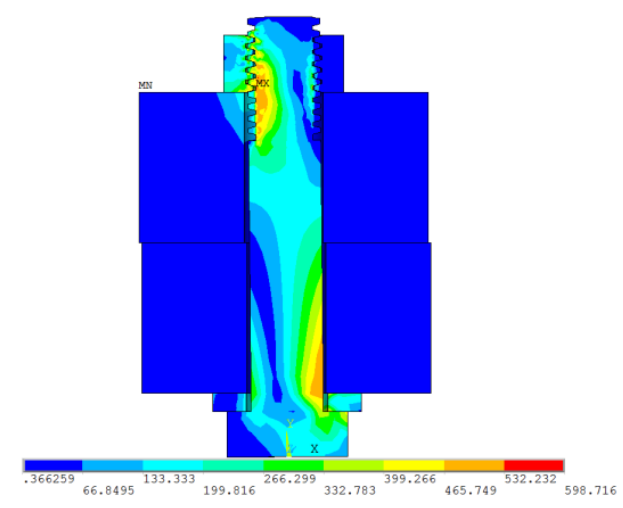

c)

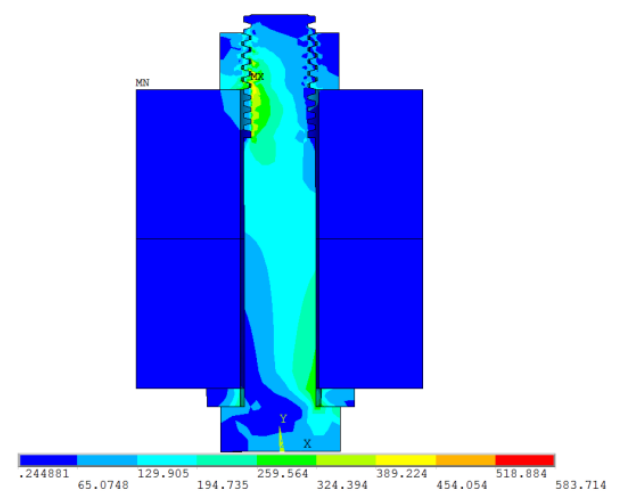

b)

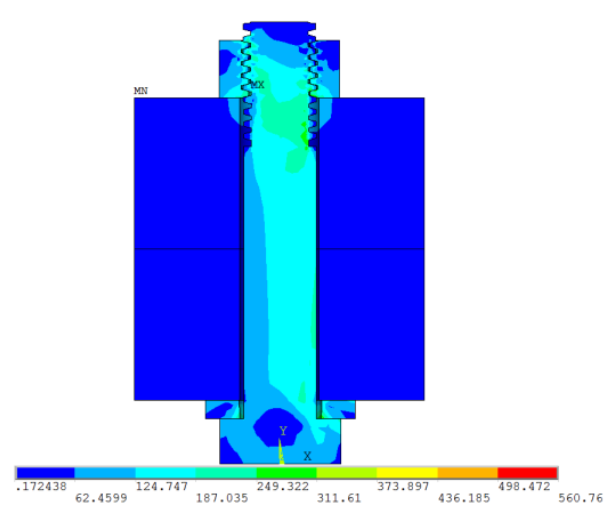

d)

Fig.5 a ) Transverse load amplitude maximum b ) Transverse load amplitude back to the origin 
c) Transverse load amplitude negative maximum

d) Transverse load amplitude back to the origin again

Secondly, changing the amplitude of transverse cyclic displacement loading, this paper analyzes the self-loosening process of bolted joints under the different amplitude of transverse cyclic displacement loading. The friction coefficient of the contacts is set as 0.3 and pre displacement is $0.08 \mathrm{~mm}$. The magnitude of the transverse cyclic displacement loading respectively is $0.46 \mathrm{~mm}$ and $0.54 \mathrm{~mm}$. Simulating six load cycles, the change of clamping force with the load cycle can be obtained as shown in Fig.6. From Fig.6, it can be concluded that the bigger of the lateral cyclic loading amplitude lead to the faster self-loosening, and remaining clamping force will be smaller.

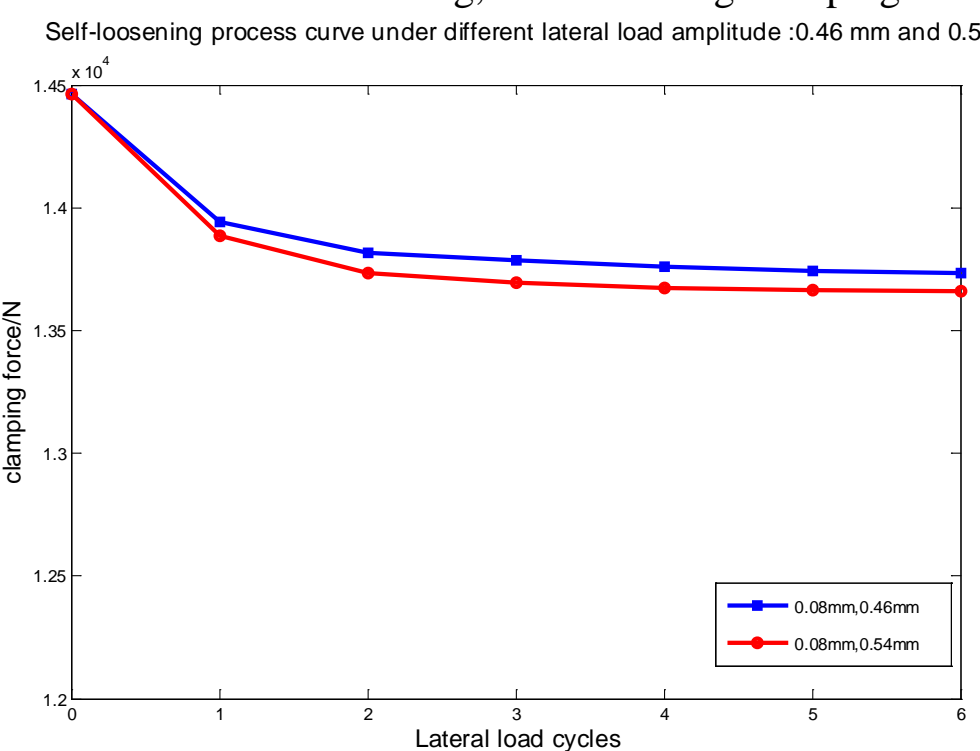

Fig.6 Self-loosening process curve under different transverse loading amplitude

Lastly, changing the friction coefficient of the clamping surface, this paper analyzes the self-loosening process of bolted joints under different friction coefficient. The friction coefficient of the contacts respectively is set as 0.3 and 0.1 , pre displacement is $0.08 \mathrm{~mm}$. The magnitude of the transverse cyclic displacement loading is $0.46 \mathrm{~mm}$. Simulating six load cycles, the changes of clamping force with the load cycle can be obtained as shown in Fig.7. From Fig.7, it can be seen that there is almost no relationship between the friction coefficient of clamping surface and the self-loosening of bolted joints. Reasonable preload can effectively improve the bolt connection relaxation.

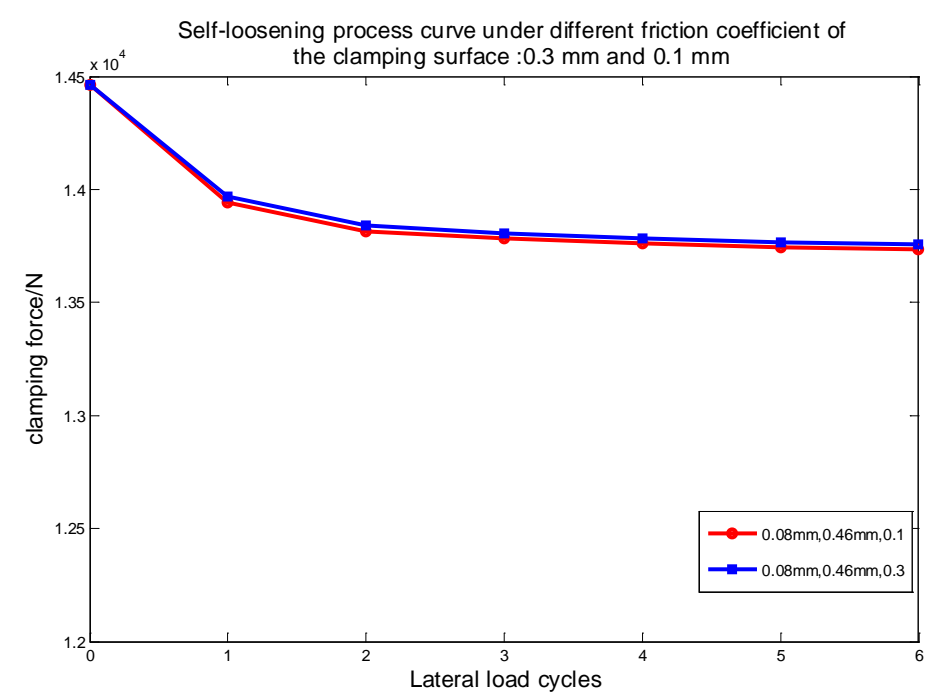

Fig.7 Self-loosening process curve under different friction coefficient of the clamping surface 


\section{Conclusion}

This paper firstly establishes the elastic finite element model, and analyzes the changes of clamping force under different pre displacement, then establishes the elastic-plastic finite element model, and simulates the process of early stage self-loosening of bolted joints under different lateral cyclic load amplitude, different initial preload, and different clamping surface friction coefficient. It mainly explains the nature of early stage self-loosening of bolted joints and analyzes the influence factors of the self-loosening process. Some conclusions can be drawn as follows:

(1) The pre displacement and clamping force of bolted joints is linearly proportional. In the range of elastic deformation, the greater is pre tension, the greater is clamping force.

(2) The early stage self-loosening of bolted joints under lateral cyclic loading is due to the accumulation of local cyclic plastic deformation at the root of the engaged thread. The accumulation of local cyclic plastic deformation leads to the loss of clamping force.

(3) The greater preload will lead to a greater remaining clamping force, but the great preload make the self-loosening more quickly. The bigger lateral cyclic load amplitude results in the faster self-loosening and smaller remaining clamping force. There is almost no relationship between the friction coefficient of clamping surface and the self-loosening of bolted joints. Reasonable preload can effectively improve the bolted connection relaxation.

\section{Acknowledgement}

This work was financially supported by the National High-tech Research and Development Program of China (Grant No. 2013CB035706); the National Natural Science Foundation of China (Grant No. 11102144); China Postdoctoral Science Foundation (Grant No. 20110491663); and the Fundamental Research Funds for the Central Universities.

\section{References}

[1] Junker, G. H, New Criteria for Self-loosening of Fasteners Under Vibration[J],1969 SAE Paper 690055, pp. 314-335.

[2] Yamamoto, A and Kasei, S., A Solution for Self-Loosening Mechanism of Threaded Fasteners under Transverse Vibration[J],1984 Bull. Jpn. Soc. Precis. Eng.,18, pp. 261-266.

[3] Sakai, T.,1978, The Friction Coefficient of Fasteners[J],1978 Bull. JSME,21, pp.333-340.

[4]Sakai, T., Investigation of Bolt Loosening Mechanisms[J],1978 Bull. JSME,21, pp. 1385-1394.

[5] Kasei, S., Ishimura, M., and Ohashi, N., On Self-loosening of Threaded Joints in the Case of Absence of Macroscopic Bearing-surface Sliding[J],1989 Bull. Jpn. Soc. Precis. Eng., 23, pp. 3136.

[6] Yanyao Jiang, Ming Zhang, Lee C-H. A study of early stage self-loosening of bolted joints [J]. ASME Journal of Mechanical Design, 2003, 125(5):518-526.

[7] Yanyao Jiang, Zhang Ming, Park T-W, Lee C-H. An experimental study of self-loosening of bolted joints [J]. ASE Journal of Mechanical Design, 2004, 126(5):925-931. 